CANIZARES, K.A.L.; RODRIGUES, J.D.; GOTO, R. Crescimento e índices de troca gasosa em plantas de pepino irrigadas com água enriquecida com CO. Horticultura Brasileira, Brasília, v.22, n.4, p.706-711, out-dez 2004.

\title{
Crescimento e índices de troca gasosa em plantas de pepino irrigadas com água enriquecida com $\mathrm{CO}_{2}$
}

\author{
Kathia A.L. Canizares; João D. Rodrigues; Rumy Goto \\ UNESP, Instit. Biociências, C. Postal 237, 18603-970 Botucatu-SP; E-mail: kalcaniza@ hotmail.com
}

\begin{abstract}
RESUMO
Avaliou-se o efeito do enriquecimento da água de irrigação com $\mathrm{CO}_{2}$ sobre índices fisiológicos de desenvolvimento e troca gasosa de folhas de plantas de pepino do tipo japonês, cultivados em ambiente protegido. Os experimentos realizados em duas épocas do ano foram instalados em delineamento experimental de blocos ao acaso com 4 tratamentos e 5 repetições. Os tratamentos foram constituídos pelos híbridos Hokuho e Tsuyataro, irrigados com água comum ou enriquecida com $\mathrm{CO}_{2}$, em uma concentração de $1 \%$ no primeiro e $0,25 \%$ o no segundo experimento. A produção de massa de material seco e área foliar adotaram tendência exponencial, não sendo possível observar o início da diminuição da taxa de produção de massa do material seco aos 63 dias após transplante (DAT). A taxa de crescimento da comunidade e taxa de crescimento relativa do híbrido Hokuho irrigado com água comum foi diferente do irrigado com água enriquecida com $\mathrm{CO}_{2}$, no entanto, no híbrido Tsuyataro foram semelhantes. A taxa de assimilação líquida atingiu a máxima pendente na fase de crescimento vegetativo e floração, e foi reduzida drasticamente após os 20 DAT no híbrido Hokuho, e após os 35 DAT no híbrido Tsuyataro. A razão de área foliar diminuiu ligeiramente nos dois híbridos com o desenvolvimento do cultivo. No início observaram-se diferenças entre irrigação com água comum e enriquecida com $\mathrm{CO}_{2}$, porém após 20 DAT não se apreciaram mais diferenças. Quanto a troca gasosa, a taxa assimilatória líquida de $\mathrm{CO}_{2}$ e de transpiração, conductância estomática e eficiência no uso da água foram semelhantes entre plantas irrigadas com água comum e enriquecida com $\mathrm{CO}_{2}$ durante o primeiro semestre. Já no segundo semestre, maiores valores foram registrados pelas plantas irrigadas com água enriquecida.
\end{abstract}

Palavras-chave: Cucumis sativus L., fisiologia, dióxido de carbono.

\begin{abstract}
Growth analysis and gaseous exchange in cucumber plants irrigated with carbon dioxide enriched water
\end{abstract}

Experiments under protected cultivation, in two sowing dates, were set up to evaluate the effect of irrigation water enriched or not with $\mathrm{CO}_{2}$, on physiological indices and gaseous exchange of leaves of Japanese cucumber plants. The experimental design was of randomized blocks, with four and five replications. The treatments consisted of the hybrids Hokuho and Tsuyataro, irrigated with water enriched or not with $\mathrm{CO} 2,1 \%$ in the first semester and $0,25 \%$ in the second. Dry mass weight and leaf area presented an exponential tendency. The beginning of mass production decrease on dry matter, 63 days after transplanting date (DAT), was not possible to be observed. The growth rate and relative growth rate response of hybrid Hokuho differed between treatments, however, for hybrid Tsuyataro the response was similar. The net assimilation rate reached the pending maxim in the phase of vegetative growth and flowering, and was reduced drastically after 20 DAT for hybrid Hokuho, and after the 35 DAT for hybrid Tsuyataro. The leaf area rate from both hybrids decreases lightly during the cultivation, without differences between enriched and non enriched water after 20 DAT. The $\mathrm{CO}_{2}$ assimilation transpiration rate, stomatal conductance and water use efficiency were similar among plants irrigated with enriched and non enriched water during the first semester. Already in the second semester, higher values were observed in plants irrigated with enriched water.

Keywords: Cucumis sativus L., physiology, carbon dioxide.

\section{(Recebido para publicação em 25 de setembro de 2003 e aceito em 7 de junho de 2004)}

$\mathrm{N}_{\mathrm{L}}^{\circ}$ o Brasil o pepino (Cucumis sativus L.), principalmente do tipo japonês, é cultivado intensamente em ambiente protegido. Com a utilização desses ambientes surgiram grandes benefícios, principalmente para os pequenos e médios produtores, pelo cultivo intensivo e alta produtividade. Com a possibilidade de produzir em épocas que normalmente seriam impróprias e com a intenção de aumentar ainda mais a produção, ocasionado pelo aumento da eficiência fotossintética das plantas (Heij e Uffelen, 1984; Nederhoff, 1990; Lorenzo-Mínguez e Maroto, 1990), alguns desses horticultores estão enriquecendo o ambiente de cultivo com dióxido de carbono $\left(\mathrm{CO}_{2}\right)$.
Teoricamente o enriquecimento da atmosfera da estufa com $\mathrm{CO}_{2}$ promove a diminuição da respiração, fotorespiração e aumenta a fotossíntese, levando ao maior desenvolvimento das plantas (Nilsen, 1983; Heij e Uffelen, 1984; Nederhoff, 1990; LorenzoMínguez e Maroto, 1990). Nas hortaliças, este enriquecimento aumentaria a biomassa, a absorção de nutrientes e massa foliar e diminuiria a massa específica, em virtude do aumento de açúcares nas folhas pelo incremento de carboidratos que se armazenam nestes órgãos, aumentando assim a qualidade de frutos e produtividade de alface, berinjela, morango, melão, pepino, pimen- tão, repolho, tomate, e algumas espécies de flores e plantas ornamentais cultivadas em ambiente protegido com controle das condições ambientais (Nilsen, 1983; Heij e Uffelen, 1984; Nederhoff, 1990; Lorenzo-Mínguez e Maroto, 1990; Letard, 1996; Reinert et al., 1997). Na agricultura brasileira esta situação não acontece, pois as estruturas destinadas à produção comercial apresentam apenas efeito guarda-chuva. Portanto, para o produtor brasileiro seria pouco viável o enriquecimento via atmosfera, mas, o enriquecimento com $\mathrm{CO}_{2}$ (gás) via irrigação poderia ser uma possibilidade de uso se comprovadas as vantagens da sua utilização, nessas condições tropicais, 
tanto de clima quanto de estruturas agrícolas. Dessa forma e a partir dessa realidade, pesquisadores brasileiros junto a produtores vêem no fornecimento de $\mathrm{CO}_{2}$ via irrigação uma possibilidade de benefício às hortaliças, como demostraram pesquisas realizadas no Canadá, Creta, Espanha, Estados Unidos, Holanda, Israel, Japão, África do Sul (Enoch, 1990; Nederhoff, 1990; Novero et al., 1991; Storlie e Heckman, 1996; Mavrogianopoulos, et al., 1999; Merwe e Cramer, 2000; Cramer et al., 2001).

No Brasil existem alguns experimentos realizados com alface, abobrinha, melão, pimentão, e tomate, com enriquecimento de $\mathrm{CO}_{2}$ via irrigação, onde foram observadas diferentes respostas (Machado et al., 1999; Pinto et al., 2000; Gomes, 2001; Kano, 2002; Cararo e Duarte, 2002; Furlan et al., 2002; Araújo, 2002; Rezende et al., 2003).

A análise de crescimento se baseia no fundamento de que aproximadamente $90 \%$ da matéria seca acumulada pelas plantas ao longo do seu crescimento, resulta da atividade fotossintética. Partindo do princípio de que a análise de crescimento das plantas é o meio mais acessível e bastante preciso para avaliar o crescimento e inferir a contribuição de diferentes processos fisiológicos sobre o comportamento vegetal (Benincasa, 1988), e de que aplicação do gás na água de irrigação poderia afetar o desenvolvimento (Storlie e Heckman, 1996) das plantas, pretendese com este experimento obter e fornecer informações sobre a aplicação de $\mathrm{CO}_{2}$ na água de irrigação, avaliando o efeito do seu uso sobre os índices fisiológicos de desenvolvimento e troca gasosa de plantas de pepino cultivadas em ambiente protegido.

\section{MATERIAL E MÉTODOS}

Os experimentos foram conduzidos durante o primeiro e segundo semestre de 2002, na UNESP em Botucatu, em ambiente protegido, utilizando-se uma estrutura de metal tipo arco de 7 x 40 $\mathrm{m}$, com 3,8 $\mathrm{m}$ de altura de pé direito, coberta com agrofilme de $150 \mathrm{~mm}$ aditivado e inicialmente fechada nas la- terais com tela de sombreamento de $75 \%$ e saia de filme plástico. As laterais foram parcialmente abertas durante o $2^{\circ}$ semestre para amenizar a temperatura diurna.

Na parte interna e central do ambiente protegido foi feita uma divisória de 1,0 $\mathrm{m}$ de altura, utilizando filme de polietileno, ficando assim a área experimental dividida, metade com água enriquecida, e a outra metade com água comum. Esta decisão foi tomada em consequiência de observações prévias (Guimarães e Rodrigues, 2002), onde tinha sido verificada a eficiência da divisória; não havendo possibilidade de contaminação com $\mathrm{CO}_{2}$ via irrigação na outra metade do ambiente.

Com base na análise química do solo, fez-se a correção da sua acidez e adubação inicial, seguindo critérios de Trani e Raij (1997) e Canizares et al. (2002). O solo do local correspondeu a um podzolico com textura arenosa, com pH 6,1 a 6,5 após a correção no primeiro semestre e 6,1 e 6,6 no segundo semestre. No primeiro semestre foi utilizado $40 \mathrm{~g} \mathrm{~m}^{-2}$ de calcário dolomítico PRNT 90, $280 \mathrm{~g} \mathrm{~m}^{-1}$ de superfosfato simples, $0,6 \mathrm{~g} \mathrm{~m}^{-1}$ de nitrato de magnésio e $0,06 \mathrm{~g}$ $\mathrm{m}^{-1}$ de ácido bórico. No segundo semestre unicamente se utilizou $150 \mathrm{~g} \mathrm{~m}^{-1} \mathrm{de}$ superfosfato simples. A adubação em cobertura foi semanal nos quatro experimentos, à base de uréia ou nitrato de cálcio ou nitrato de potássio, na concentração de $0,5 \%$ de $\mathrm{N}$, dissolvido em água e distribuído com copos plásticos.

Semeou-se em março (primeiro semestre) e em julho (segundo semestre), em bandejas de poliestireno expandido modelo $128 / 6$, contendo o substrato à base de terra (Ballarim, 1996 citado por Canizares et al., 2002). Transplantouse após duas semanas em espaçamento de $1,0 \times 0,5 \mathrm{~m}$. No solo foi colocada cobertura morta à base de acículas de pinus visando a diminuição da evaporação da água.

Aos 5 dias foi iniciada a aplicação do dióxido de carbono (entre as 8:00 e 10:00 horas), na concentração de $1 \mathrm{~g} \mathrm{~L}^{-1}$ (1\%o) na água de irrigação através da rede de irrigação. No $1^{\circ}$ semestre o $\mathrm{CO}_{2}$ foi injetado $12 \mathrm{~L} \mathrm{~min}^{-1}$ durante 1 hora de irrigação. No segundo semestre foi injetado $3 \mathrm{~L} \mathrm{~min}^{-1}(0,25 \%$ ), durante 1 hora de irrigação, aumentando o tempo de irrigação nos dias mais quentes. $\mathrm{O}$ experimento que não recebeu $\mathrm{CO}_{2}$ foi irrigado com a mesma freqüência e quantidade de água. Para essa finalidade foi utilizado um bujão de dióxido de carbono líquido sob pressão $(5 \mathrm{~kg})$, provido de manômetro $\left(\mathrm{L} \mathrm{min}^{-1}\right)$ e injetor Venturi específico para aplicação de gás em água, localizados fora do ambiente protegido.

As brotações dos primeiros cinco nós da planta foram retiradas. As plantas foram tutoradas individualmente, conduzidas até o $22^{\circ}$ nó, e todas as ramificações secundárias foram despontadas com 2 entrenós.

O delineamento experimental foi em blocos ao acaso com 4 tratamentos: híbridos Hokuho e Tsuyataro, irrigados com água comum e enriquecida com $\mathrm{CO}_{2}$, com 4 repetições e 3 plantas úteis/ parcela. Com as características massa seca da parte aérea e área foliar aos 6; 10; 20; 35 e 63 dias após transplante, foi feita a análise funcional (programa Anacres), calculando os índices taxa de crescimento da comunidade (TCC), taxa de crescimento relativo (TCR), taxa assimilatória líquida (TAL), razão de área foliar (RAF). Também foram determinados os índices de troca gasosa, taxa assimilatória (A), conductância estomâtica (Gs), eficiência do uso da água (EUA) e taxa de transpiração (E) na quinta folha a partir do ápice, em duas épocas (20 e 50 DAT) utilizando-se para tal efeito um analisador de $\mathrm{CO}_{2}$ por radiação infra-vermelha ("Infra Red Gas Analyser-IRGA", modelo Li-6200, LICOR). Foram feitas as análises individuais e conjunta seguindo os critérios de Banzatto e Kronka (1989). As médias foram comparadas pelo teste de Tukey a $5 \%$.

\section{RESULTADOS E DISCUSSÃO}

$\mathrm{Na}$ análise conjunta da massa seca da parte aérea e da área foliar dos experimentos, não foi possível observar diferenças estatísticas. Na análise funcional dessas características (Figura 1) foi possível ajustar os dados a um modelo quadrático, concordando com LorenzoMinguez (1994). Estes resultados diferem de Guri et al. (1999) citado por 


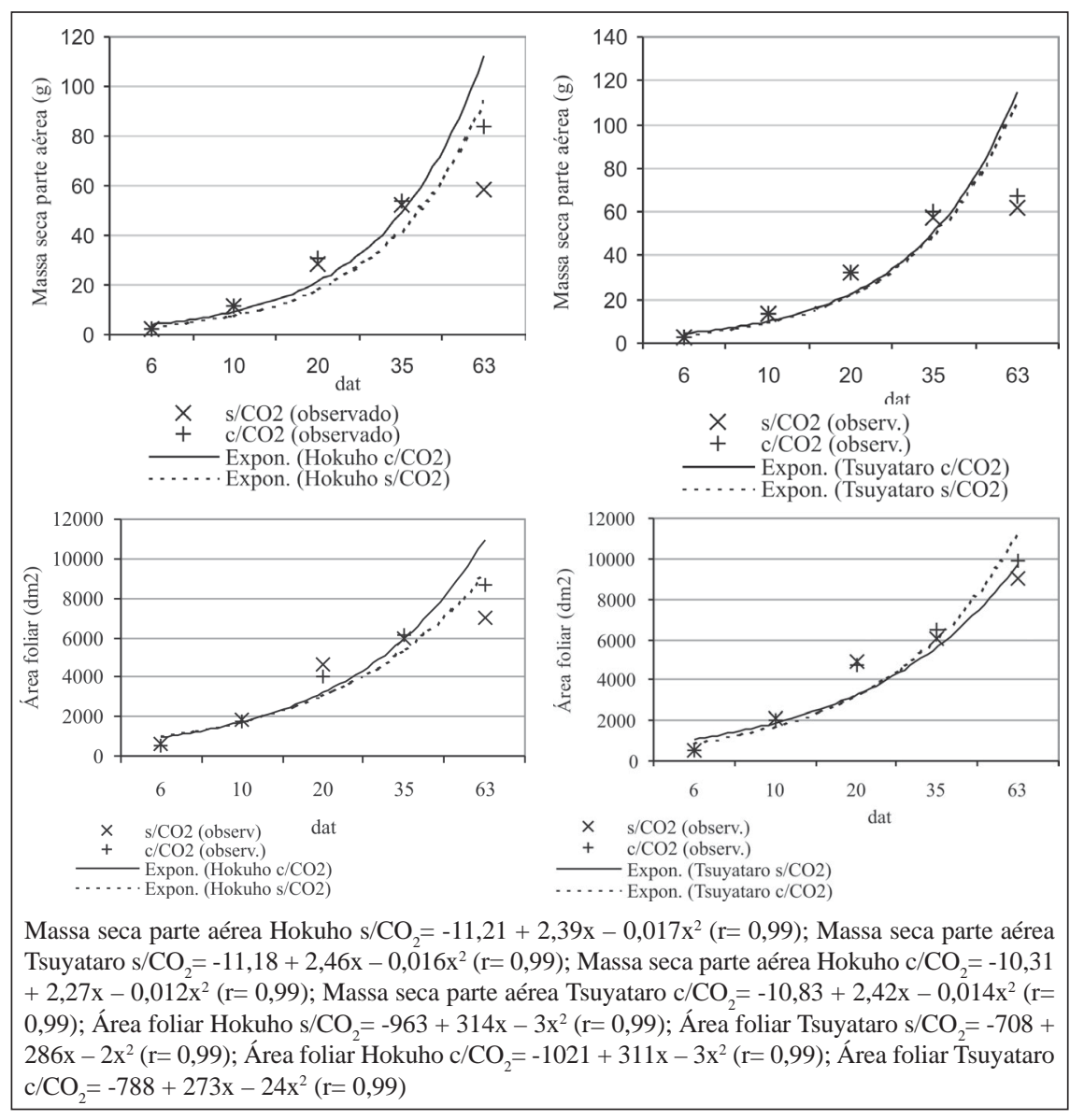

Figura 1. Massa seca da parte aérea $(\mathrm{g})$ e área foliar (dm2) calculadas e observadas em plantas de pepino irrigadas com água enriquecida de $\mathrm{CO}_{2}$. UNESP, São Manuel, Botucatu, 2003.

Galvani (2001) que observaram incrementos de área foliar de pimentão em função do $\mathrm{CO}_{2}$ via hidroponia e de Araújo (2002) que obteve aumento da massa do material seco e da área foliar em plantas de abobrinha irrigadas com água enriquecida com $\mathrm{CO}_{2}$.

A produção de massa do material seco da parte aérea adotou tendência exponencial, coincidindo com a fase de desenvolvimento dos órgãos vegetativos, iniciando 20 DAT o desenvolvimento dos primeiros frutinhos. Não foi possível observar o início da diminuição da taxa de produção de massa do material seco devido a que a última avaliação feita foi aos 63 DAT, quando a planta ainda estava em crescimento vegetativo e plena produção (Figura 1). Da mesma forma, não foi possível observar as variações das taxas de crescimento no período de colheita, alternando períodos de altas taxas de crescimento de frutos e redução de crescimento vegetativo e vice versa, como observado por Marcelis (1993) e Galvani (2001).
A taxa de crescimento da comunidade (TCC) ou eficiência produtiva da comunidade, e taxa de crescimento relativa (TCR) foram diferentes no híbrido Hokuho irrigado com enriquecida ou não, porém, semelhantes para o híbrido Tsuyataro, mostrando o potencial de resposta do híbrido Hokuho frente à utilização de água enriquecida com $\mathrm{CO}_{2}$ (Figura 2).

A TCC e TCR foram altas aos 6 DAT, devido a uma característica própria do pepineiro, pois neste estádio junvenil as plantas crescem muito em relação à sua massa. Depois os índices diminuíram até o menor valor aos 63 DAT (Figura 2), devido possivelmente à diminuição da radiação incidente e interceptada pelo cultivo (Lorenzo-Minguez, 1994). Neste contexto, esse autor observou queda da TCC a partir dos 65 dias após semeadura, em plantas de pepino sob ambiente protegido.

A taxa de assimilação líquida (TAL), componente fisiológico que relaciona a fotossíntese com a respiração, atingiu a máxima pendente na fase de crescimento vegetativo e floração, e foi reduzida drasticamente após os 20 DAT no híbrido Hokuho, e após os 35 DAT no híbrido Tsuyataro. Em plena fase de crescimento vegetativo, o híbrido Hokuho apresentou diariamente fotossíntese líquida de 2,7 a $2,8 \mathrm{mg} \mathrm{dm}^{-2}$ e o híbrido Tsuyataro entre 2,5 e $2,9 \mathrm{mg} \mathrm{dm}^{-2}$ (sem e com $\mathrm{CO}_{2}$ ), chegando ao final do ciclo a 0,04 e $0,08 \mathrm{mg} \mathrm{dm}^{-2} \mathrm{dia}^{-1}$ e o híbrido Tuyataro entre 0,06 e $0,07 \mathrm{mg} \mathrm{dm}^{-2} \mathrm{dia}^{-1}$ (sem e com $\mathrm{CO}_{2}$ ) (Figura 3).

O componente morfológico razão de área foliar (RAF), evolucionou diminuindo ligeiramente com o desenvolvimento do cultivo. A RAF de ambos híbridos, aos 6 DAT, apresentou diferenças, porém, aos 20 DAT não se apreciaram mais diferenças (Figura 3). Segundo Gifford e Evans (1981), Marcelis (1993) e Lorenzo-Minguez, (1994), os índices de crescimento observados em plantas de pepino cultivadas em ambiente protegido, evidenciam a competência dominante que os frutos exercem. Em conseqüência, a maior proporção da fração vegetativa formada na fase inicial do cultivo, acontece quando a intensidade da radiação incidente sobre o dossel vegetal é menos limitante, assim, as diferenças entre as plantas se acentuam menos.

Sendo a planta de pepino de crescimento indeterminado, que inicialmente inverte uma grande quantidade de assimilados nas folhas para poder realizar e manter a alta taxa de fotossíntese, e frutos que reduzem o crescimento das partes vegetativas a partir da frutificação (Gifford e Evans, 1981) a análise de crescimento funcional foi ajustada à forma exponencial seguindo os critérios de LorenzoMinguez, 1994). Porém, Yang et al. (1990) citado por Lorenzo-Minguez, (1994) realizaram ajustes de IAF utilizando modelos lineares e Galvani (2001) realizou o ajuste do IAF por modelos polinomiais de $3^{\mathrm{a}}$ e $4^{\mathrm{a}}$ ordem.

Quanto aos índices de troca gasosa, na análise conjunta verificou-se que a taxa assimilatória líquida no primeiro semestre foi semelhante entre plantas irrigadas com água comum e enriquecida com $\mathrm{CO}_{2}$. Já no segundo semestre, foi possível observar no final 
do ciclo, maior taxa nas plantas irrigadas com água enriquecida (Figura 4). Segundo Lorenzo-Minguez (1994) a taxa de assimilação aumenta até um valor a partir do qual incrementos posteriores de radiação fotossinteticamente ativa não proporcionam aumentos na taxa de fotossintese (A).

A mesma pesquisadora cita Tichá et al. (1985) que afirmam que a taxa fotossintética é maior nas folhas da base de plantas jovens; no entanto, em plantas adultas, a taxa é maior nas folhas intermediárias, e nas plantas velhas, a taxa é maior na parte superior da planta.

$\mathrm{Na}$ análise conjunta da conductância estomâtica das folhas, houve queda da Gs em ambos semestres, sendo que no primeiro semestre, valores mais altos foram registrados pelas plantas irrigadas com água comum, porém, no final do ciclo desse semestre e durante as duas avaliações do segundo semestre, as plantas irrigadas com água enriquecida com $\mathrm{CO}_{2}$, apresentaram maiores índices de Gs (Figura 4).

A conductância estomatica é recíproca à resistência estomatica, e varia em função do processo difusivo da fase gasosa, aberturas estomaticas e assimilação fotossintética do mesófilo (Wong et al., 1979). Por outro lado, Segundo Field (1987) citado por Lorenzo-Minguez (1994), o Gs diminui em algumas espécies antes que (A) em função da sensibilidade a mudanças ambientais, fenológicas e manipulações artificiais que diminuem a transpiração e aumentam a disponibilidade de nutrientes.

$\mathrm{Na}$ análise da taxa de transpiração (E) houve queda considerável nos dois semestres, sendo que no início do ciclo do primeiro semestre as plantas irrigadas com água comum apresentaram maior taxa de transpiração que as irrigadas com água enriquecida com $\mathrm{CO}_{2}$, porém com valores semelhantes no final do ciclo do mesmo semestre. No segundo semestre, as plantas irrigadas com água enriquecida transpiraram mais que as irrigadas com água comum, no início e final do ciclo (Figura 4).

Na análise da eficiência do uso da água (EUA) houve aumento no decorrer do ciclo das plantas, no primeiro e segundo semestre. No início do primeiro semestre não foi possível observar diferenças, po-

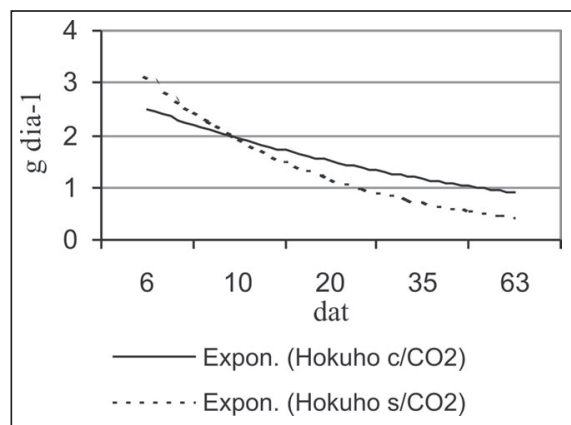

TCC

Hokuho $\mathrm{s} / \mathrm{CO}_{2}=5,15^{-0,49 \mathrm{x}}\left(\mathrm{R}^{2}=0,73\right)$

Hokuho $\mathrm{c} / \mathrm{CO}_{2}=3,24^{-0,29 \mathrm{x}}\left(\mathrm{R}^{2}=0,81\right)$

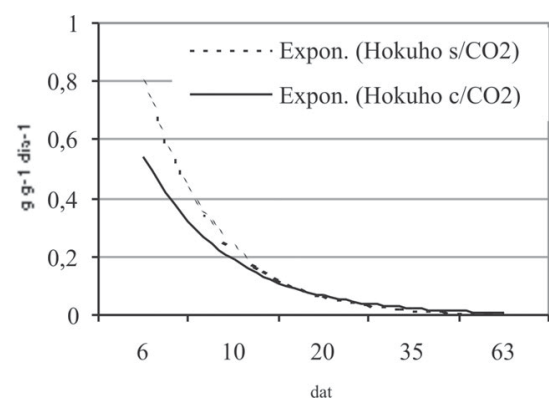

TCR

Hokuho $\mathrm{s} / \mathrm{CO}_{2}=2,77^{-1,28 \mathrm{x}}\left(\mathrm{R}^{2}=0,97\right)$

Hokuho $\mathrm{c} / \mathrm{CO}_{2}=1,58^{-1,06 x}\left(\mathrm{R}^{2}=0,98\right)$

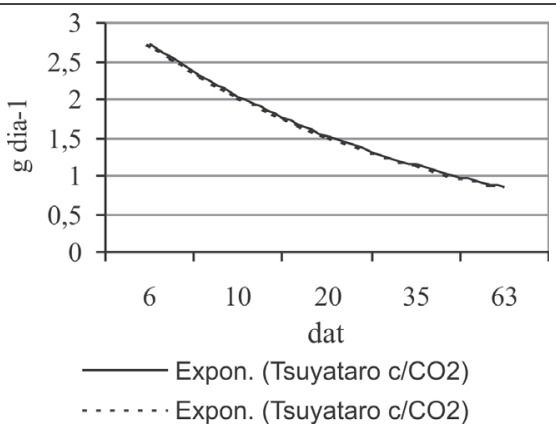

Tsuyataro $\mathrm{s} / \mathrm{CO}_{2}=4,20^{-0,36 \mathrm{x}}\left(\mathrm{R}^{2}=0,77\right)$

Tsuyataro $\mathrm{c} / \mathrm{CO}_{2}=3,65^{-0,29 \mathrm{x}}\left(\mathrm{R}^{2}=0,80\right)$

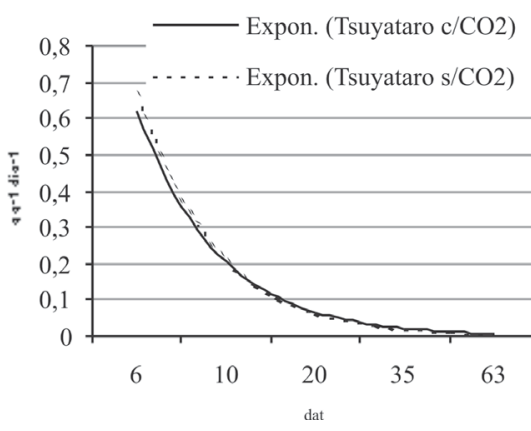

Tsuyataro $\mathrm{s} / \mathrm{CO}_{2}=2,15^{-1,17 \times} 9 \mathrm{R}^{2}=0,990$

Tsuyataro $\mathrm{c} / \mathrm{CO}_{2}=1,91^{-1,12 \mathrm{x}}\left(\mathrm{R}^{2}=0,990\right.$

Figura 2. Taxa de crescimento da comunidade (TCC) em $\mathrm{g} \mathrm{dia}^{-1} \mathrm{e}$ taxa de crescimento da relativa (TCR) em g g ${ }^{-1}$ dia $^{-1}$ de plantas de pepino irrigadas com água enriquecida de $\mathrm{CO}_{2}$. UNESP, São Manuel, Botucatu, 2003.

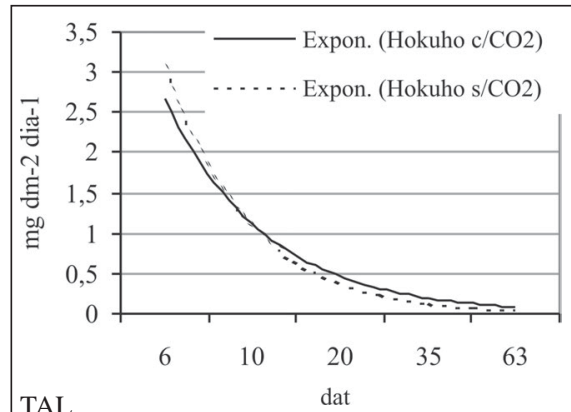

TAL

dat

Hokuho $\mathrm{s} / \mathrm{CO}=8,62^{-1,04 x}\left(\mathrm{R}^{2}=0,98\right)$

Hokuho $\mathrm{c} / \mathrm{CO}_{2}=6,42^{-0,87 x}\left(\mathrm{R}^{2}=0,99\right)$

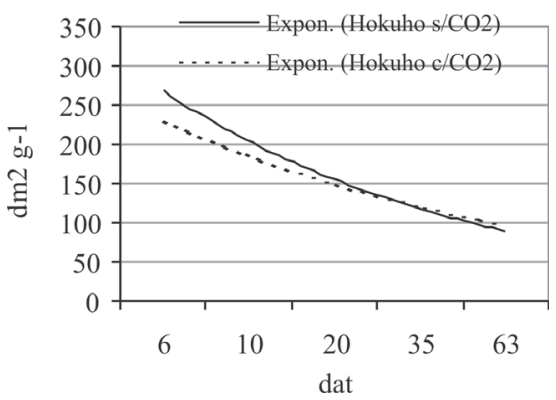

RAF

Hokuho $\mathrm{s} / \mathrm{CO}_{2}=352,62^{-0,27 \times}\left(\mathrm{R}^{2}=0,90\right)$

Hokuho $\mathrm{c} / \mathrm{CO}_{2}=287,04^{-0,21 \times}\left(\mathrm{R}^{2}=0,92\right)$

Figura 3 Taxa assimilatória líquida (TAL) em $\mathrm{mg} \mathrm{dm}^{-2} \mathrm{dia}^{-1} \mathrm{e}$ razão de área foliar (RAF) em $\mathrm{dm}^{2} \mathrm{~g}^{-1}$ de plantas de pepino irrigadas com água enriquecida de $\mathrm{CO}_{2}$. UNESP, São Manuel, Botucatu, 2003.

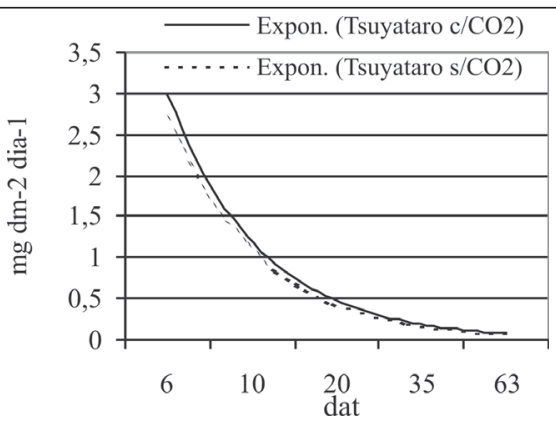

Tsuyataro $\mathrm{s} / \mathrm{CO}_{2}=6,72^{-0,91 \times}\left(\mathrm{R}^{2}=0,99\right)$ Tsuyataro $\mathrm{c} / \mathrm{CO}_{2}=7,49^{-0,92 \times}\left(\mathrm{R}^{2}=0,99\right)$

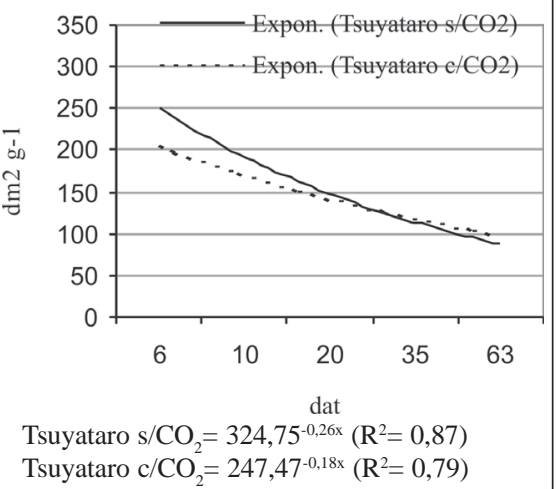

Tsuyataro $\mathrm{s} / \mathrm{CO}_{2}=324,75^{-0,26 x}\left(\mathrm{R}^{2}=0,87\right)$ Tsuyataro $\mathrm{c} / \mathrm{CO}_{2}=247,47^{-0,18 x}\left(\mathrm{R}^{2}=0,79\right)$ 


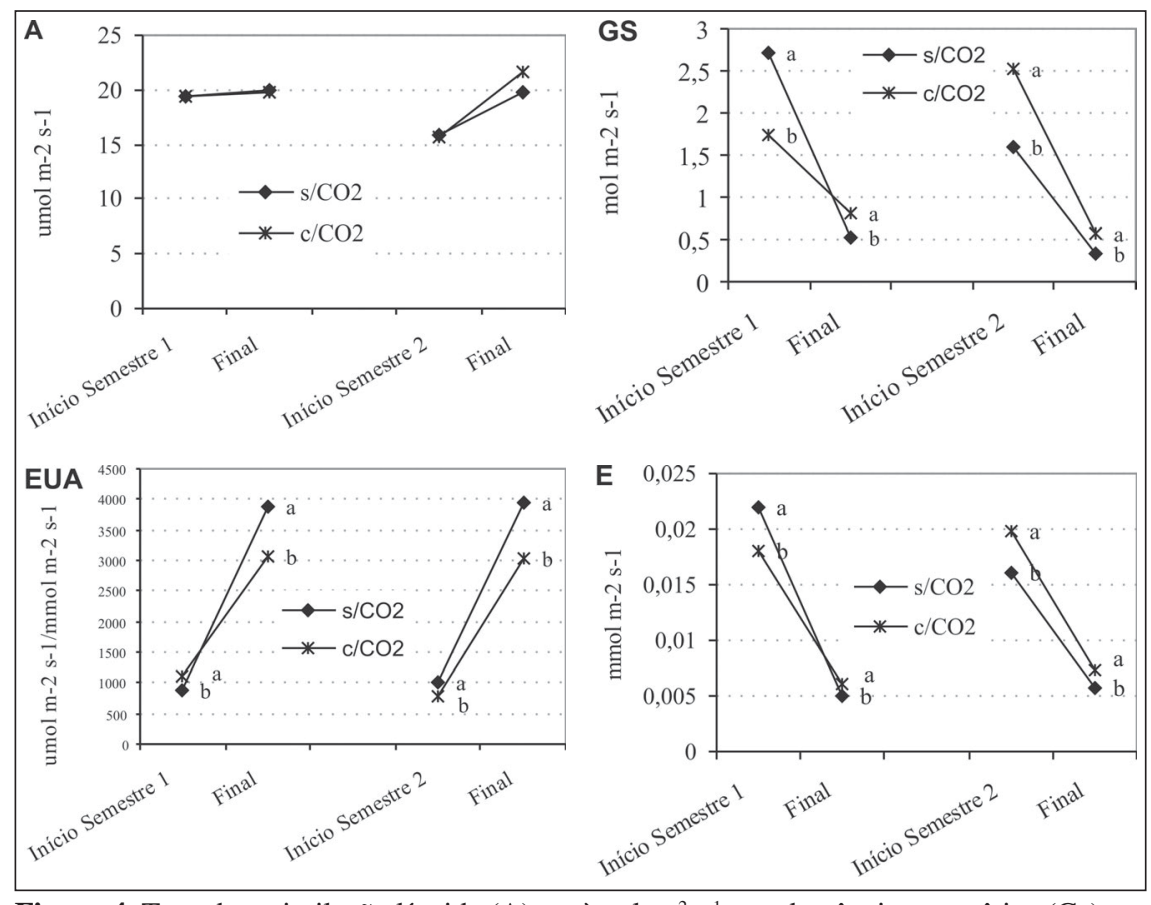

Figura 4. Taxa de assimilação líquida (A) em ìmol $\mathrm{m}^{-2} \mathrm{~s}^{-1}$, conductância estomâtica (Gs) em mol m $\mathrm{m}^{-2} \mathrm{~s}^{-1}$, eficiência do uso da água (EUA) em ìmol m $\mathrm{m}^{-2} \mathrm{~s}^{-1} / \mathrm{mol} \mathrm{m}^{-2} \mathrm{~s}^{-1} \mathrm{e}$ taxa de transpiração (E) em mmol m$~^{-2} \mathrm{~s}^{-1}$ de plantas de pepino irrigadas com água enriquecida ou não de $\mathrm{CO}_{2}$, cultivadas em dois semestres. UNESP, São Manuel, Botucatu, 2003.

rém ao final do ciclo, as plantas irrigadas com água comum apresentaram maiores índices, mantendo esta tendência no segundo semestre (Figura 4).

Segundo Ito (1978) e Wofe (1994) citados por Guimarães e Rodrigues (2002) o aumento da EUA é produzido pela queda da Gs e E e devido à manutenção da taxa fotossintética das plantas, mesmo com o fechamento parcial dos estômatos; por outro lado, quando a concentração de $\mathrm{CO}_{2}$ aumenta, geralmente diminui a condutância estomatica. Da mesma forma, quando a concentração de $\mathrm{CO}_{2}$ é alta, o aumento instantâneo da eficiência do uso da água é relacionado com a conductância e transpiração.

A redução de Gs diminui a transpiração que provoca incremento da temperatura foliar (Lorenzo-Minguez, 1994). A mesma autora cita Losch e Tenhunen (1981), que afirmaram que a conductância estomatica (Gs) é influenciada pelas condições de evapotranspiração ambiental e independente da taxa de transpiração (E) embora possa ser afetada eventualmente.

A planta de pepino pertence ao grupo das $\mathrm{C}_{3}$ (Lorenzo-Minguez, 1994). A concentração de $\mathrm{CO}_{2}$ intercelular depende do fluxo de $\mathrm{CO}_{2}$ através do estômato e está determinado pela concentração do $\mathrm{CO}_{2}$ ambiental, taxa de assimilação líquida (A) e condutância estomatica (Gs) (Morison, 1985 citado por LorenzoMinguez, 1994).

Em síntese, no presente experimenapresentaram diferenças estatísticas nos índices da análise de crescimento, porém, houve diferenças nos índices de troca gasosa: condutância estomatica, eficiência do uso da água e taxa de transpiração; indicando grande potencial dos híbridos de produzirem mais ou menos, influenciados pelo enriquecimento da água. No início do primeiro semestre, a taxa de Gs inferior em plantas irrigadas com água enriquecida com $1 \%$ o de $\mathrm{CO}_{2}$, pode indicar a possibilidade de melhor aproveitamento no processo nutricional, por permitir maior disponibilidade de nutrientes. No início do segundo semestre o resultado foi contrário, sendo que nesse ciclo, as plantas receberam $0,25 \%$ o de $\mathrm{CO}_{2}$. via água de irrigação.

Sendo este o primeiro trabalho experimental em pepineiro irrigado com água enriquecida com $\mathrm{CO}_{2}$ no Brasil, to, os híbridos Hokuho e Tsuyataro não recomendam-se outras pesquisas, diversificando os genótipos e as concentrações de $\mathrm{CO}_{2}$, objetivando estabelecer uma tecnologia viável e simples, e sobretudo, com vantagens econômicas e ambientais.

\section{AGRADECIMENTOS}

À FAPESP pelo apoio financeiro.

\section{LITERATURA CITADA}

ARAÚJO W.F. Aplicação de água carbonatada em abobrinha cultivada em solo com e sem cobertura plástica. Piracicaba, 2002.86 p. (Tese doutorado), ESALQ, USP.

BANZATTO, D.A.; KRONKA, S.N. Experimentação Agrícola. São Paulo: UNESP, 1989, p.247. BENINCASA, M.M.P. Análise de crescimento de plantas. Jaboticabal: FUNEP, 1988, p.42.

CANIZARES, K.A.L; COSTA, P.C.; GOTO, R.; VIEIRA, A.R.M. Desenvolvimento de mudas de pepino em diferentes substratos com e sem uso de solução nutritiva. Horticultura Brasileira, Brasília, v.20, n.2, p.227-229, 2002.

CARARO, D.C.; DUARTE, S.M. Injeção de CO e lâminas de irrigação em tomateiro sob estufa. Horticultura Brasileira, Brasília, v.20, n.3, p.432437, 2002.

CRAMER, M.D.; OBERHOLZER, J.A.; COMBRINK, N.J.J. The effect of supplementation of root zone dissolved inorganic carbon on fruit yield and quality of tomatoes (cv. Daniella) grown with salinity. Scientia Horticulturae, v.89, p.269-289, 2001. ENOCH, H.Z. Crop responses to aerial carbon dioxide. Acta Horticulturae, v.268, p.17-32, 1990. FURLAN, R.A.; REZENDE, F.C.; ALVES, D.R.B.; FOLEGATTI, M.V. Lâmina de irrigação e aplicação de $\mathrm{CO}_{2}$ na produção de pimentão cv. Mayala, em ambiente protegido. Horticultura Brasileira, Brasília, v.20, n.4, p.547-550, 2002.

GALVANI, E. Avaliação agrometeorológica do cultivo de pepino (Cucumis sativus L.) em ambientes protegido e a campo, em ciclos de outonoinverno e primavera-verão. Botucatu, 2001. 124 p. (Tese doutorado) FCA, UNESPaulista.

GIFFORD, R.M.; EVANS L.T. Photosynthesis, carbon partitioning and field. Annual Review of Plant Physiology, v.32, p.485-509, 1981.

GOMES, T.M. Efeito do $\mathrm{CO}_{2}$ aplicado na água de irrigação e no ambiente sobre a cultura da alface (Lactuca sativa L.). Piracicaba, 2001. 83 p. (Tese doutorado)ESALQ, USP.

GUIMARÃES, V.F.; RODRIGUES, J.D. Respostas fisiológicas do tomateiro ao enriquecimento com dióxido de carbono, via água de irrigação, em cultivo protegido. Botucatu, 2002. 62 p. Relatório Científico (Pós-Doutorado) UNESP.

HEIJ, G.; UFFELEN, J.A.M. Effects of $\mathrm{CO}_{2}$ concentration on growth and production of glasshouse vegetable crops. Acta Horticulturae, v.148, p.591-595, 1984.

KANO. C. Extrações de nutrientes pelo meloeiro rendilhado cultivado em ambiente protegido com adição de potássio e $\mathrm{CO}_{2}$. Piracicaba, 2002. 102 p. (Dissertação mestrado) ESALQ, USP. 
LETARD, M. Use of $\mathrm{CO}_{2}$ in the greenhouse: plant behavior and $\mathrm{CO}_{2}$ consumption. Infos-Paris, $\mathrm{Pa}$ ris, v.123, p.32-7, 1996.

LORENZO-MINGUEZ, P. Intercepción de luz, bioproductividad e intercambio gaseoso durante la ontogenia del cultivo de pepino (Cucumic sativus L.) en invernadero. Almeria, Junta de Andalucia, 1994, $255 \mathrm{p}$.

LORENZO-MINGUEZ, P.; MAROTO, C. $\mathrm{CO}_{2}$ in plastic greenhouse in Almeria (Spain). Acta Horticulturae, v.268, p.165-167, 1990.

MACHADO, E.C.; TAKANE, R.J.; FERRO, R. Aplicação de $\mathrm{CO}_{2}$ via água de irrigação em agricultura. In: FOLEGTTI, M.V. (Coord.) Fertirrigação: citrus, flores, hortaliças. Guaíba: Agropecuária, 1999. p.345-353.

MARCELIS, L.F.M. Fruit growth and biomass allocation to the fruits in cucumber, 2. Effect of irradiance. Scientia Horticulturae, v.54, p.123130, 1993.

MAVROGIANOPOULOS, G.N.; SPANAKIS, J.; TSIKALAS, P. Effect of carbon dioxide enrichment and salinity on photosynthesis and yield in melon. Scientia Horticulturae, v.79, p.5163, 1999.
MERWE, C.A.V.; CRAMER, M.D. Effect enriched rhizosphere carbon dioxide on nitrate and ammonium uptake in hydroponically grown tomato plants. Plant and Soil, v.221, p.5-11, 2000. NEDERHOFF, E.M. Technical aspects, management and control of $\mathrm{Co}_{2}$ enrichment in greenhouses. Acta Horticulturae, v.268, p.127138, 1990.

NILSEN, S.; HOVLAND, K.; DONS, C.; SLETTEN, S.P. Effect of $\mathrm{CO}_{2}$ enrichment on photosynthesis, growth and yield of tomato. Scientia Horticulturae, v.20, p.1-14, 1983.

NOVERO, R.; SMITH, D.H.; MOORE, F.D.; SHANAHAN, J.F.; D'ANDRIA, R. Field growth tomato response to carbonated water application. Agronomy Journal, v.83, n.5, p.911-916, 1991.

PINTO, J.M.; BOTREL, T.A.; MACHADO, E.C. Uso do dióxido de carbono na agricultura: revisão bibliográfica. Ciência Rural, Santa Maria, v.30, n.4, p.919-925, 2000.

REINERT, R.A.; EASON, G.; BARTON, J. Growth and fruiting of tomato as influenced by elevated carbon dioxide and ozone. New Phytologist, v.137, p.411-420, 1997.
REZENDE, F.C.; FRIZZONE, J.A.; OLIVEIRA, R.F.; PEREIRA, A.S. $\mathrm{CO}_{2}$ and irrigation in relation to yield and water use of the bell pepper crop. Scientia Agrícola, v.60, n.1, p.7-12, 2003.

STORLIE, C.A.; HECKMAN, J.R. Bell Pepper yield response to carbonated irrigation water. Journal of Plant Nutrition, v.19, n.10-11, p.14771484, 1996.

TRANI P.E.; RAIJ, B. Hortaliças. In: RAIJ, B.; CANTARELLA, H.; QUAGGIO, J.A.; FURLANI, A.M.C. Boletim Técnico Instituto Agronômico: Recomendações de adubação $e$ calagem para o Estado de São Paulo. 2 ed., Campinas, IAC, p.165, 1997.

WONG, S.C.; COWAN, I.R.;FARQUHAR, G.D. Stomatal conductance correlates with photosynthetic capacity. Nature, v.282, p.424-426, 1979. 